\title{
Preparatory Preparations for the Study of Drug Therapies for Emergency Diseases
}

\author{
Chang Rok Jeong* \\ Adjunct professor, Kyoungpook National University, Department of Ethics Education, Teacher's College, Buk-guSangyeok 3(sam)-dong \\ Daegu City, South Korea
}

Received: 制June 10, 2018; Published: 眥 June 18, 2018

*Corresponding author: Chang Rok Jeong, Department of Ethics Education, Teacher's College, Kyoungpook National University, BukguSangyeok 3(sam)-dong 702-701, Daegu City, South Korea

\begin{abstract}
In the US, more than 400,000 medical treatments are carried out each year to eliminate intestinal adhesion. The economic loss from these medical treatments is estimated to be about $\$ 1.2$ billion. This economic loss has been significant, and the search results from pub med under keyword Intestinal Obstruction have been decreasing since 2015. It is difficult to research and prevent a disease caused by small intestine, which is one of the emergency diseases. Because emergency diseases have structural problems that are very difficult to collect and analyze data for research. Emergency care measures, especially drug development, require a platform that allows public funding and sharing of clinical data. Emergency diseases have scattered clinical data. The research into this emergency disease requires a method of receiving clinical data as a condition to provide free medical treatment to patients through the IRB. There is an urgent need to find the reverse data. Modern society is a time of the Fourth Industrial Revolution. Above all, AI, Deep Learning, and platforms are important keywords. In these times, open and international cooperation is necessary for the safety of emergency patients such as intestinal obstruction. Development guidelines describe how medicine will overcome these shortcomings during the Fourth Industrial Revolution.
\end{abstract}

Keywords: An emergency disease; Intestinal Obstruction; Deep Learning; Platforms; International Cooperation; Development guidelines for drug development; Ethical guidelines

\section{Introduction}

On November 21, 2010, a four-year-old girl visited the emergency room of Kyungpook national university hospital and could not receive treatment because she did not have a pediatrician. The girl was diagnosed with intestinal obstruction, but died while looking for other hospitals that could perform surgery [1]. Since this incident, the Korean medical community has come to think not about medical technology but about the problems of the medical delivery system. On October 17, 2014, the famous Korean singer, Hae-chul Shin, passed away after undergoing a intestinal stenosis surgery (enterolysis). In both cases, if the patient suffers an acute attack and is not treated quickly, it is caused by intestinal complications that can lead to death. However, in these two cases, I would like to point out that the lack of treatment method and medication development for emergency patients is also the cause of the incident. And I want to suggest how medicine will overcome these shortcomings during the 4th Industrial Revolution $[2,3]$.

\section{The Present State of Study on Emergency Diseases: Focus on Intestinal Obstruction}

Patients who have laparoscopic surgery experience symptoms of enteroplegia from adhesions. And patients also get various diseases such as pain and intestinal obstruction. The disease caused by intestinal obstruction is one of the major problems that are difficult to research and prevent. In the U.S., more than 400,000 medical treatments are carried out each year to eliminate intestinal adhesion. The economic loss from these medical treatments is estimated to be about $\$ 1.2$ billion [4]. The table shows the results of a search using the keyword 'Intestinal Obstruction' on the pubmed with such a large economic loss. The column is the number of papers and the length is the year. As shown in the table, the number of research papers has been decreasing since 2015, as shown in Table 1. This means that there is little sense of problem in this field. Why is this? 
Table 1: Changes over the years of a thesis from Pubmed to the keyword Intestinal Observation.

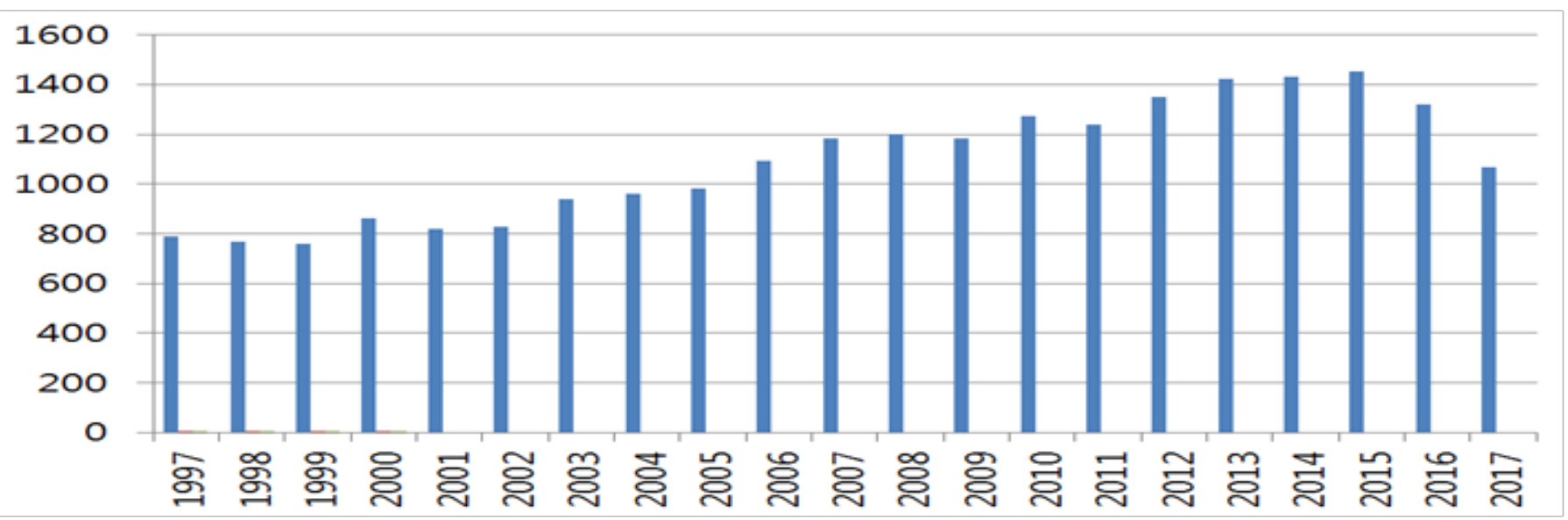

Why Is It Difficult to Study Emergency Diseases?

I want to find the reason for that in the nature of disease. I consider the difference between emergency and chronic diseases as follows.

\section{The Need for International Funds and Platforms for the Treatment of Emergency Diseases and Drug Development}

As I looked at the papers on this topic, I felt that emergency care methods, especially for drug development, need to have a platform to share public funding and clinical data because emergency disease has scattered clinical data.

a. The research into this emergency disease requires a method of receiving clinical data as a condition to provide free medical treatment to patients through the IRB. b. There is an urgent need to find the reverse data. Modern society is a time of the Fourth Industrial Revolution. Above all, AI, Deep Learning, and platforms are important keywords. In these times, open and international cooperation is necessary for the safety of emergency patients such as intestinal superposition. Because, as shown in Table 2, emergency conditions, such as intestinal overlay, take less time from disease occurrence to death and are difficult to collect clinical data because of the relatively high mortality rate compared to chronic diseases. The IRB, which is needed for research on human beings, is also unlikely to pass due to time. I think it is difficult to study because of this nature of emergency disease. To overcome these shortcomings, international cooperation is needed above all else. And guidelines for studying these diseases are needed in advance.

Table 2: Comparison of emergency and chronic diseases.

\begin{tabular}{|c|c|c|c|c|c|c|}
\hline & $\begin{array}{c}\text { Time from } \\
\text { disease } \\
\text { occurrence to } \\
\text { death }\end{array}$ & $\begin{array}{c}\text { Risk from disease } \\
\text { occurrence to } \\
\text { death if treatment } \\
\text { is difficult }\end{array}$ & $\begin{array}{c}\text { Ease of clinical } \\
\text { data collection }\end{array}$ & $\begin{array}{c}\text { The IRB's ability } \\
\text { to pass through }\end{array}$ & Research material & $\begin{array}{c}\text { Clinical data } \\
\text { integration }\end{array}$ \\
\hline $\begin{array}{c}\text { An emergency } \\
\text { disease }\end{array}$ & to be short & high & to be difficult & $\begin{array}{c}\text { Be comparatively } \\
\text { difficult }\end{array}$ & $\begin{array}{c}\text { Be comparatively } \\
\text { small }\end{array}$ & $\begin{array}{c}\text { Be poorly } \\
\text { integrated }\end{array}$ \\
\hline A chronic disease & to be long & Low & to be easy & $\begin{array}{c}\text { Be comparatively } \\
\text { easy }\end{array}$ & $\begin{array}{c}\text { Be comparatively } \\
\text { large }\end{array}$ & $\begin{array}{c}\text { Be highly } \\
\text { integrated }\end{array}$ \\
\hline
\end{tabular}

\section{Conclusion: Proposal of International Cooperation} Guidelines for the Study of Emergency Disease

I lived in Daegu, one of the cities in South Korea, and I was very sad to hear that a child with intestinal obstruction had died. And I was very sad to hear that Great Korean singer Hae-chul Shin died by intestinal obstruction. I was his fan like many people in Korea. In the future, I would like to suggest the following for children and for great singers with intestinal obstruction. I think the following suggestions can be helpful to researchers who study intestinal obstruction. I think that the following are the international guidelines for promoting research on emergency diseases, such as intestinal obstruction. a) Unification of the Clinical Data Format: Prepare the Deep Learning method by unifying different languages into common languages such as English and PDF or other kinds of paper files into the same as MS Word files. At this time, the paper on emergency and rare diseases is given priority.

b) Integration of the Report: A comprehensive study of current drug assessment and special cases and follow-up research data is required.

c) Prepare a system to provide integrated data from developed countries for each emergency. And through the platform, you can access these materials anytime, anywhere. 
The Information Committee on the treatment of emergency diseases and drug development shall provide integrated guidelines for emergency care to developing countries every year.

d) When clinical data of developing countries are used as research data in advanced countries, the government should protect them by considering their privacy measures. If the developing country does not have any special privacy measures, it is required to combine international and national guidelines.

e) With the help of international funds, these studies allow certain researchers to receive the IRB in advance and execute it through the integration guidelines.

\section{References}

1. (2012) http://www.breaknews.com/sub_read.html?uid=220864 Brake news. Daegu has a child care clinic for the night holiday.

2. (2014) YTN news, death of singer Shin Hae-cheol who was treated for intensive care unit.

3. Yoon-Hwa Hong, Won SukLee, Jeong-HeumBaek, Jung-NamLee, WoonKiLee, et al. (2011) Clinical comparison about post-operative bowel function recovery between Seprafilm and Adept which used in colorectal cancer operation as an adhesion reduction agents. Korean Journal of Clinical Oncology 7(2): p.70

4. Ray NF, Denton WG, Thamer M, Henderson SC, Perry S (1998) Abdominal adhesiolysis: inpatient care and expenditures in the United States in 1994. J Am Coll Surg 186(1):1-9.

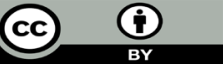

This work is licensed under Creative Commons Attribution 4.0 License

Submission Link:

Submit Article

DOI: 10.32474/DDIPIJ.2018.01.000121

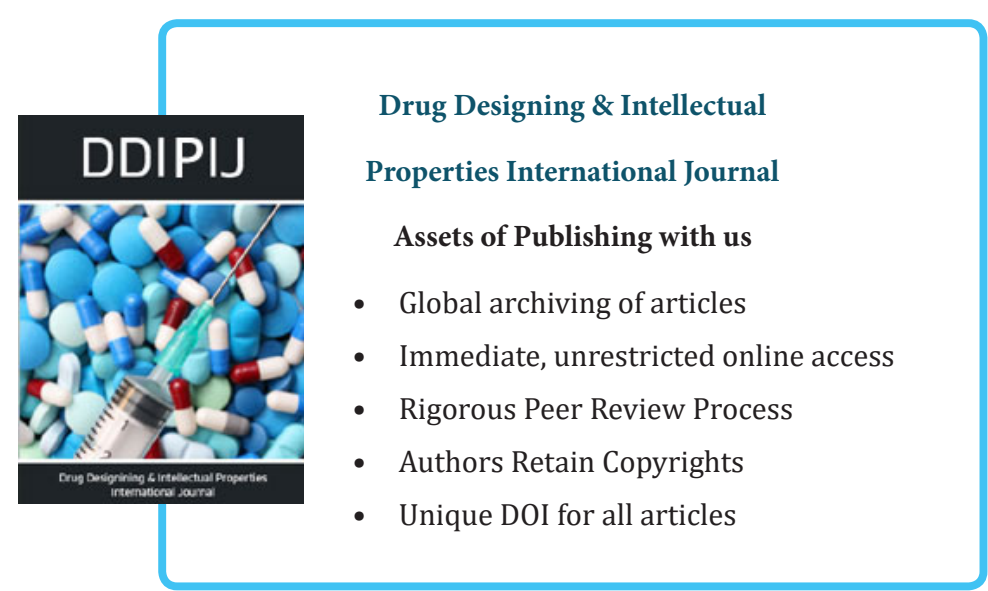

